\title{
Article
}

\section{Purification of Lithium Chloride Solution and Fractionation Property for Lithium Isotopes of Niobate Crystal}

\author{
*Yoji Makita, Junji Hosokawa, Akinari Sonoda, Kohji Sakane, Kenta Ooi and Takahiro Hirotsu \\ Health Technology Research Center, AIST, 2217-14 Hayashi, Takamatsu, 761-0395, Japan
}

(Manuscript submitted April 17, 2007; accepted June 25, 2007)

\begin{abstract}
The selectivity of crystalline $\left(\mathrm{H}_{3} \mathrm{O}\right)_{8} \mathrm{Nb}_{22} \mathrm{O}_{59}$ for alkali metal ions was, based on a batch method, in the order of $\mathrm{Li}^{+}>>\mathrm{K}^{+}>\mathrm{Na}^{+}, \mathrm{Rb}^{+}>>\mathrm{Cs}^{+}$in alkaline solutions and $\mathrm{K}^{+}>>\mathrm{Na}^{+}, \mathrm{Rb}^{+}>>\mathrm{Li}^{+}, \mathrm{Cs}^{+}$in acidic solutions at $\mathrm{pH}<3.5$. The column elution of a lithium chloride solution containing 236 and $72 \mathrm{mg}$ $\mathrm{dm}^{-3}$ of $\mathrm{Na}^{+}$and $\mathrm{K}^{+}$, respectively, through the niobate bed, caused extreme decreases of $\mathrm{Na}^{+}$and $\mathrm{K}^{+}$ concentrations to less than $0.1 \mathrm{mg} \mathrm{dm}^{-3}$ up to 200 and above 400 bed volumes, respectively, with rarely change of the $\mathrm{Li}^{+}$concentration. Fractionation of lithium isotopes with the niobate was also investigated by both the batch and column methods. It had a relatively high separation factor of 1.026. The column fractionation study showed that ${ }^{7} \mathrm{Li}$ was enriched in the front part of the elution band and ${ }^{6} \mathrm{Li}$ in the rear part, with the maximum and minimum ${ }^{7} \mathrm{Li} /{ }^{6} \mathrm{Li}$ ratios of 15.0 and 11.2 , respectively.
\end{abstract}

Key words: ion exchange, niobate, purification, lithium chloride, lithium isotope, separation factor

\section{Introduction}

Lithium chemicals are widely used in lots of product such as high energy storage lithium battery, heat-resistant glass, surface acoustic wave filter, and drug medicine of manic-depressive. Lithium isotopes also are essential to operate a nuclear power plant. The lithium element consists of two stable isotopes, ${ }^{6} \mathrm{Li}$ and ${ }^{7} \mathrm{Li}$, in the natural state. The heavier isotope, ${ }^{7} \mathrm{Li}$, is used in the form of ${ }^{7} \mathrm{LiOH}$ in order to control the $\mathrm{pH}$ of boric acid solution injected as cooling water into the reactor core of the nuclear power generation. The lighter isotope, ${ }^{6} \mathrm{Li}$, is considered for the tritium breeder blanket of nuclear fusion generation which is currently under development.

The demand of lithium chemicals is increasing yearly. Seawater is considered as a vast source of lithium, although the lithium concentration in seawater is as low as about $0.17 \mathrm{mg} \mathrm{dm}^{-3}$. Several studies on lithium recovery from seawater have been done.[1-3] A novel ion-exchanger, $\mathrm{H}_{1.6} \mathrm{Mn}_{1.6} \mathrm{O}_{4}$, has been developed, which is the most suitable to date for lithium recovery owing to its high selectivity toward lithium ions, its large adsorptive capacity and its high chemical stability.[4] Since the adsorbent uptakes not only lithium ions mainly but also slightly other elements of sodium, potassium, magnesium and calcium ions from seawater, the recovered lithium solution, which is obtained by desorption of lithium from the adsorbent with acid solution, contains these minor elements. Thus, it is necessary to eliminate such impurities from the lithium solution in order to obtain a highly-pure lithium compound. $\mathrm{Rb}_{8} \mathrm{Nb}_{22} \mathrm{O}_{59}$ shows a unique ion-exchange behavior with smooth $\mathrm{Rb}^{+} / \mathrm{Na}^{+}$and $\mathrm{Rb}^{+} / \mathrm{K}^{+}$exchanges while no $\mathrm{Rb}^{+} / \mathrm{Li}^{+}$exchange in an alkali metal chloride solution.[5] In our previous paper, we reported ion-exchange property of $\left(\mathrm{H}_{3} \mathrm{O}\right)_{8} \mathrm{Nb}_{22} \mathrm{O}_{59}$ which is obtained by acid-treatment of the precursor, 
$\mathrm{Rb}_{8} \mathrm{Nb}_{22} \mathrm{O}_{59}$, and demonstrated that the niobate can uptake only sodium and potassium ions from a matrix of lithium chloride solution by a batch method.[6]

In the present study, we report purification of a lithium solution by chromatography with the niobate, and it is discussed with the result of the $\mathrm{pH}$ dependence of selectivity for alkali metal ions by batch experiments. We also report lithium isotope selectivity of the niobate and chromatographic lithium isotope separation. Some inorganic ion-exchangers have been reported to have relatively high separation factors for lithium isotope,[7-12] and the lithium isotope fractionation of ion-exchanger has been often discussed in relation to the affinity toward alkali metal ions. An ion-exchanger with high affinity to $\mathrm{Li}^{+}$and/or $\mathrm{Na}^{+}$tends to have a large $S$ value.[7,9,10] From the unique ion exchange behavior of $\left(\mathrm{H}_{3} \mathrm{O}\right)_{8} \mathrm{Nb}_{22} \mathrm{O}_{59}$, we can expect that it shows high lithium isotope fractionation effect, since it has high affinity not only for $\mathrm{K}^{+}$ions but also for $\mathrm{Na}^{+}$ions.

\section{Experimental}

\subsection{Materials}

Niobate crystal, $\left(\mathrm{H}_{3} \mathrm{O}\right)_{8} \mathrm{Nb}_{22} \mathrm{O}_{59}$, was prepared by a heating method similar to that in the literature.[6] The starting material, $\mathrm{Rb}_{8} \mathrm{Nb}_{22} \mathrm{O}_{59}$, was prepared by heating a stoichiometric mixture of $\mathrm{Rb}_{2} \mathrm{CO}_{3}(>97 \%$, Wako Chem. Co. Ltd.) and $\mathrm{Nb}_{2} \mathrm{O}_{5}\left(99.9 \%\right.$, Wako Chem. Co. Ltd.) at $1200{ }^{\circ} \mathrm{C}$ for 24 hours. The as-prepared $\mathrm{Rb}_{8} \mathrm{Nb}_{22} \mathrm{O}_{59}$ was crushed and sieved in size from 63 to $300 \mu \mathrm{m}$. The sieved sample $(600 \mathrm{~g})$ was acid-treated with a $10 \mathrm{MHNO}_{3}$ solution $\left(3 \mathrm{dm}^{3}\right)$ for 16 hours. The acid-treatment was carried out four times in order to extract $\mathrm{Rb}^{+}$ions completely to form $\left(\mathrm{H}_{3} \mathrm{O}\right)_{8} \mathrm{Nb}_{22} \mathrm{O}_{59}$ by $\mathrm{Rb}^{+} / \mathrm{H}_{3} \mathrm{O}^{+}$exchange. After the acid treatment, the solid was washed thoroughly with deionized water and dried at $70{ }^{\circ} \mathrm{C}$. X-ray diffraction (XRD) patterns of the starting material $\mathrm{Rb}_{8} \mathrm{Nb}_{22} \mathrm{O}_{59}$ and the final product $\left(\mathrm{H}_{3} \mathrm{O}\right)_{8} \mathrm{Nb}_{22} \mathrm{O}_{59}$ agreed with those in the previous paper.[6] The XRD patterns were measured using a RINT 2100 (Rigaku Co. Ltd.).

\subsection{Distribution Coefficient $\left(K_{d}\right)$}

$100 \mathrm{mg}$ of the ion-exchanger, $\left(\mathrm{H}_{3} \mathrm{O}\right)_{8} \mathrm{Nb}_{22} \mathrm{O}_{59}$, ground in an agate mortar was immersed in $10 \mathrm{~cm}^{3}$ of a mixed solution of $1 m M\left(M=\right.$ mol dm$\left.{ }^{-3}\right) \mathrm{XCl}$ and $\mathrm{XOH}(\mathrm{X}=\mathrm{Li}, \mathrm{Na}, \mathrm{K}, \mathrm{Rb}$, and $\mathrm{Cs})$ with various ratio of $\mathrm{Cl}^{-} / \mathrm{OH}^{-}$. After intermittent shaking for 2 days, the $K_{\mathrm{d}}$ values were calculated as:

$$
K_{d}\left(\mathrm{~cm}^{3} \mathrm{~g}^{-1}\right)=\frac{\text { metal ion uptake }\left(\mathrm{mmol} \mathrm{g}^{-1}\right)}{\text { metal ion concentration }\left(\mathrm{mmol} \mathrm{cm}^{-3}\right)}
$$

Each metal ion concentration in the supernatant solution was determined by atomic absorption spectrophotometry (AAS) using a AAnalyst 300 (Parkin Elmer Co. Ltd.). The metal ion uptake was calculated from the residual ion concentration of the solution. The $\mathrm{pH}$ of the solution after adsorption was measured by a pH meter.

\subsection{Column Chromatography for Purification of Lithium Chloride Solution}

An $\left(\mathrm{H}_{3} \mathrm{O}\right)_{8} \mathrm{Nb}_{22} \mathrm{O}_{59}$ (70.4 $\mathrm{g}$ of dry weight) slurry was packed in the full space of a chromatographic glass column (10 mm in diameter and $500 \mathrm{~mm}$ in length). The bed volume of niobate was $39 \mathrm{~cm}^{3}$. This paper defines the bed volume as one $B V$. A feed solution which contains 3290, 236 and $72 \mathrm{mg} \mathrm{dm}^{-3}$ of $\mathrm{Li}^{+}, \mathrm{Na}^{+}$and $\mathrm{K}^{+}$, respectively, was prepared by dissolving $\mathrm{LiCl}, \mathrm{NaCl}$ and $\mathrm{KCl}$ in deionized water. $\mathrm{A} 15 \mathrm{dm}^{3}$ of the feed solution was passed downward through the column at a flow rate of $11.8 \mathrm{~cm}^{3} \mathrm{~h}^{-1}$ (space velocity $=0.30 \mathrm{~h}^{-1}$ ) at $25^{\circ} \mathrm{C}$ with a peristaltic pump. The effluent was collected by every $10 \mathrm{~cm}^{3}$ fractions using an automatic sample collector. The metal ion concentrations in selected fractions were measured by a usual method for $\mathrm{Li}^{+}$and by a standard addition method for $\mathrm{Na}^{+}$and $\mathrm{K}^{+}$. The $\mathrm{pH}$ in the selected fractions was also measured by $\mathrm{pH}$ meter.

\subsection{Lithium Isotopic Separation Factor $(S)$}

The lithium isotopic separation factor, $S$, was measured by a batch method. The niobate $(0.28,0.46$ or 
$1.00 \mathrm{~g}$ ) was immersed in $10 \mathrm{~cm}^{3}$ of a mixed solution of $0.03 \mathrm{M} \mathrm{LiCl}$ and $0.07 \mathrm{M} \mathrm{LiOH}$, shaken intermittently for 3 days at $25{ }^{\circ} \mathrm{C}$ and then filtered. The $S$ value was calculated using the following equation:

$$
S=\frac{\left({ }^{7} \mathrm{Li} /{ }^{6} \mathrm{Li}\right)_{\text {solution }}}{\left({ }^{7} \mathrm{Li} /{ }^{6} \mathrm{Li}\right)_{\text {solid }}}
$$

where $\left({ }^{7} \mathrm{Li} /{ }^{6} \mathrm{Li}\right)_{\text {solution }}$ and $\left({ }^{7} \mathrm{Li} /{ }^{6} \mathrm{Li}\right)_{\text {solid }}$ are the lithium isotopic ratios in the solution and solid phases, respectively. The $\left({ }^{7} \mathrm{Li} /{ }^{6} \mathrm{Li}\right)_{\text {solid }}$ can be calculated from the lithium isotopic ratios and the lithium ion concentrations of the solution before and after the ion-exchange reaction. The lithium ion uptake was calculated from the residual ion concentration of the solution which was measured by AAS. The $S$ value was actually calculated using the following equation:

$$
S=\frac{\alpha(1+\alpha) C_{0}-\alpha\left(1+\alpha_{0}\right) C}{\alpha_{0}(1+\alpha) C_{0}-\alpha\left(1+\alpha_{0}\right) C}
$$

where $\alpha_{0}$ and $C_{0}$ are ${ }^{7} \mathrm{Li} /{ }^{6} \mathrm{Li}$ isotopic ratio and lithium ion concentration, respectively, before adsorption and $\alpha$ and $C$ are those after adsorption. To determine the ${ }^{7} \mathrm{Li} /{ }^{6} \mathrm{Li}$ isotopic ratio by surface ionization mass spectrometry, the starting solution and the filtrate were converted to $\mathrm{LiOH}$ solution by passing through a column of anion-exchange resin (Amberlite CG-400, Organo Co. Ltd.), and then to LiI solution by addition of HI solution to the $\mathrm{LiOH}$ solution. The lithium isotopic ratio was measured using a VG336 with a wide flight tube (V.G. Co. Ltd.). The relative standard deviation of the ${ }^{7} \mathrm{Li} /{ }^{6} \mathrm{Li}$ measurement was less than $0.11 \%$.

\subsection{Chromatography for Lithium Isotope Separation}

A chromatographic column was prepared as in the section 2.3. The $\mathrm{Li}^{+}$exchanged band was formed at the top of the bed by passing down $0.05 \mathrm{MCH}_{3} \mathrm{COOLi}\left(240 \mathrm{~cm}^{3}\right)$ at a flow rate of $12 \mathrm{~cm}^{3} \mathrm{~h}^{-1}$ at $25{ }^{\circ} \mathrm{C}$ with a double-plunger pump. After rinsing out the liquid in the column with deionized water, $0.1 \mathrm{MHNO}_{3}$ was then fed at the flow rate of $12 \mathrm{~cm}^{3} \mathrm{~h}^{-1}$, to elute the exchanged lithium ions. The eluate was collected by every $5 \mathrm{~cm}^{3}$ fractions. The lithium ion concentrations of the fractions were measured by AAS. The ${ }^{7} \mathrm{Li} /{ }^{6} \mathrm{Li}$ isotopic ratios of the fractions were measured by inductively-coupled plasma mass spectrometry (ICP-MS) with a SPQ9000 (Seiko instruments Inc.) after the eluate was diluted by $0.5 \mu \mathrm{g} \mathrm{dm}$ of lithium ion concentration with $0.1 M \mathrm{HNO}_{3}$. The isotopic ratios were corrected using the factor which was obtained from the isotopic ratios of the feed solution measured by both the surface ionization mass spectrometry and ICP-MS.

\section{Results and Discussion}

\subsection{Ion-exchange Property}

Table 1 Distribution coefficient $\left(K_{\mathrm{d}}\right)$ for alkali metal ions.

\begin{tabular}{cccccccc}
\hline \multirow{2}{*}{ Solution } & \multicolumn{3}{c}{$\log K_{\mathrm{d}} / \mathrm{cm}^{3} \mathrm{~g}^{-1}$} & \multicolumn{3}{c}{$\begin{array}{c}\mathrm{pH} \text { after } \\
\text { equilibrium } \\
\text { adsorption }\end{array}$} & Reference \\
\cline { 2 - 7 } & $\mathrm{Li}^{+}$ & $\mathrm{Na}^{+}$ & $\mathrm{K}^{+}$ & $\mathrm{Rb}^{+}$ & $\mathrm{Cs}^{+}$ & - & 5 \\
$\mathrm{~A}$ & 0.8 & 2.8 & 4.3 & 3.3 & 0.9 & 3.04 & This work \\
$\mathrm{B}$ & 1.1 & 3.1 & 3.9 & 3.6 & 1.4 & 3.47 & This work \\
$\mathrm{C}$ & 1.3 & 3.9 & 5.1 & 3.7 & 1.3 & 7.32 & 5 \\
$\mathrm{D}$ & 5.0 & 3.1 & 4.1 & 4.1 & 2.1 & 10.7 & This work \\
$\mathrm{E}$ & 5.9 & 3.4 & 4.0 & 3.4 & 1.8 &
\end{tabular}

A: $1 \mathrm{~m} M \mathrm{LiCl}+1 \mathrm{~m} M \mathrm{NaCl}+1 \mathrm{~m} M \mathrm{KCl}+1 \mathrm{~m} M \mathrm{RbCl}+1 \mathrm{~m} M$ CsCl. B: $1 \mathrm{~m} M \mathrm{LiOH}+1 \mathrm{~m} M \mathrm{NaCl}+1 \mathrm{~m} M$ $\mathrm{KCl}+1 \mathrm{~m} M \mathrm{RbCl}+1 \mathrm{~m} M$ CsCl. C: $1 \mathrm{~m} M \mathrm{LiOH}+1 \mathrm{~m} M \mathrm{NaOH}+1 \mathrm{~m} M \mathrm{KOH}+1 \mathrm{~m} M \mathrm{RbCl}+1 \mathrm{~m} M \mathrm{CsCl}$. D: $1 \mathrm{~m} M \mathrm{LiOH}+1 \mathrm{~m} M \mathrm{NaOH}+1 \mathrm{~m} M \mathrm{KOH}+1 \mathrm{~m} M \mathrm{RbOH}+1 \mathrm{~m} M$ CsOH. E: $1 \mathrm{~m} M \mathrm{LiOH}+1 \mathrm{~m} M \mathrm{NaOH}+1 \mathrm{~m} M$ $\mathrm{KOH}+1 \mathrm{~m} M \mathrm{RbOH}+3 \mathrm{~m} M \mathrm{CsOH}$. 
The $K_{\mathrm{d}}$ values for alkali metal ions of $\left(\mathrm{H}_{3} \mathrm{O}\right)_{8} \mathrm{Nb}_{22} \mathrm{O}_{59}$ at different $\mathrm{pH}$ values are given in Table 1 . The $K_{\mathrm{d}}$ value for $\mathrm{Li}^{+}$changes drastically with $\mathrm{pH}$, showing the lowest value among alkali metal ions at $\mathrm{pH}$ of less than 3 , whereas the highest at $\mathrm{pH}$ of 10.7 . In contrast, the $K_{\mathrm{d}}$ values for $\mathrm{Na}^{+}, \mathrm{K}^{+}$and $\mathrm{Rb}^{+}$are markedly high irrespective of $\mathrm{pH}$. The $K_{\mathrm{d}}$ value for $\mathrm{Na}^{+}$is similar to that for $\mathrm{Rb}^{+}$at the same $\mathrm{pH}$, and the $K_{\mathrm{d}}$ for $\mathrm{K}^{+}$is higher than those for $\mathrm{Na}^{+}$ and $\mathrm{Rb}^{+}$. The $K_{\mathrm{d}}$ for $\mathrm{Cs}^{+}$shows a low value irrespective of $\mathrm{pH}$ due to the fact that $\mathrm{Cs}^{+}$ions rarely exchange with lattice protons, but only with hydroxyl groups on the surface of $\left(\mathrm{H}_{3} \mathrm{O}\right)_{8} \mathrm{Nb}_{22} \mathrm{O}_{59}$. [6] The selectivity is thus in the order of $\mathrm{Li}^{+}>>\mathrm{K}^{+}>\mathrm{Na}^{+}, \mathrm{Rb}^{+}>>\mathrm{Cs}^{+}$at $\mathrm{pH}$ of more than 7.3 and of $\mathrm{K}^{+}>>\mathrm{Na}^{+}, \mathrm{Rb}^{+}>>\mathrm{Li}^{+}, \mathrm{Cs}^{+}$at $\mathrm{pH}$ of less than 3.5 . This result suggests that $\left(\mathrm{H}_{3} \mathrm{O}\right)_{8} \mathrm{Nb}_{22} \mathrm{O}_{59}$ uptakes $\mathrm{Na}^{+}, \mathrm{K}^{+}$and $\mathrm{Rb}^{+}$much more selectively than $\mathrm{Li}^{+}$and $\mathrm{Cs}^{+}$, when the $\mathrm{pH}$ of the mixed aqueous solution is low.

\subsection{Purification of Lithium Chloride Solution}

Figure 1 shows break through profiles of $\mathrm{Li}^{+}, \mathrm{Na}^{+}, \mathrm{K}^{+}$and a $\mathrm{pH}$ change in the chromatography of a lithium chloride solution containing minor amount of $\mathrm{NaCl}$ and $\mathrm{KCl}$. The dashed lines in the figure indicate the concentrations of $\mathrm{Li}^{+}, \mathrm{Na}^{+}$and $\mathrm{K}^{+}$ions in the feed solution. The $\mathrm{Li}^{+}$concentrations in effluent solutions are almost the same as that of the feed solution through the column experiment, indicating that $\mathrm{Li}^{+}$ions are hardly adsorbed to the niobate.

The $\mathrm{Na}^{+}$and $\mathrm{K}^{+}$ions in the feed solution can be effectively removed by passing through the niobate column although their concentrations are markedly lower than the $\mathrm{Li}^{+}$concentration. The $\mathrm{Na}^{+}$ concentration is $0.014-0.032 \mathrm{mg} \mathrm{dm}^{-3}$ at $B V<198$ and the $\mathrm{K}^{+}$concentration is $0.025-0.10 \mathrm{mg} \mathrm{dm}^{-3}$ through the column study (up to $B V$ of 382). This indicates that more than $99.98 \% \mathrm{Na}^{+}$and more than $99.8 \% \mathrm{~K}^{+}$can be removed effectively from the $\mathrm{LiCl}$ solution by only passing through the niobate column. The $\mathrm{Na}^{+} / \mathrm{Li}^{+}$and $\mathrm{K}^{+} / \mathrm{Li}^{+}$mole ratios $\left(1.7 \times 10^{-6}\right.$ in average and $2.8 \times 10^{-6}$ in average, respectively) of the effluent solution are lower than those $\left(\mathrm{Na}^{+} / \mathrm{Li}^{+}=4.0 \times 10^{-6}, \mathrm{~K}^{+} / \mathrm{Li}^{+}=4.0 \times\right.$ $10^{-6}$ ) of a commercial $\mathrm{LiCl}$ of special reagent grade (99.9\%, Wako Chem. Co. Ltd.).

The $\mathrm{Na}^{+}$concentration increases steeply at around $200 B V$ and is nearly constant at $B V>280$. The $\mathrm{pH}$ change correlates well with the change of $\mathrm{Na}^{+}$ concentration; the $\mathrm{pH}$ value increases steeply from 1.9 to 2.7 at $B V$ around 200. Accordingly the breakthrough point of $\mathrm{Na}^{+}$can be detected by monitoring the $\mathrm{pH}$ of effluent solution without measuring $\mathrm{Na}^{+}$ion concentrations of fractions. It is noticeable that the $\mathrm{Na}^{+}$ concentration ( $273 \mathrm{mg} \mathrm{dm}^{-3}$ in average) of the effluent at $B V>280$ is higher than that $\left(234 \mathrm{mg} \mathrm{dm}^{-3}\right)$ of the feed solution. The molar concentration difference of $\mathrm{Na}^{+}$is $1.70 \mathrm{mmol} \mathrm{dm}{ }^{-3}\left(39 \mathrm{mg} \mathrm{dm}^{-3}\right)$, which is close to

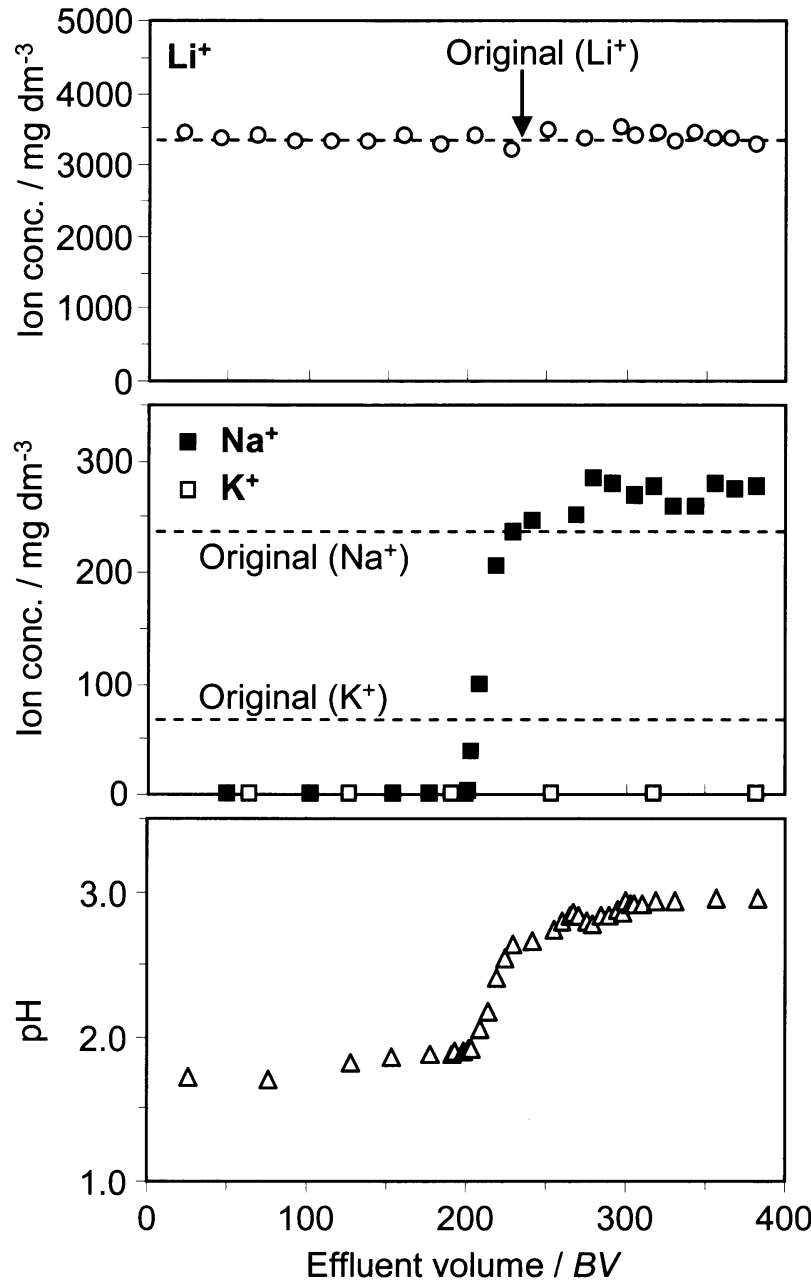

Figure 1 Break through profile of $\mathrm{Li}^{+}, \mathrm{Na}^{+}, \mathrm{K}^{+}$ and $\mathrm{pH}$ change. Ion concentrations of $\mathrm{Li}^{+}, \mathrm{Na}^{+}$and $\mathrm{K}^{+}$of feed solution are 3290,236 and $72 \mathrm{mg} \mathrm{dm}^{-3}$, respectively, and indicated by dashed line, respectively. 
the decreasing value of $\mathrm{K}^{+}$molar concentration, $1.84 \mathrm{mmol} \mathrm{dm}^{-3}\left(72 \mathrm{mg} \mathrm{dm}^{-3}\right)$. This correlation suggests that the exchanged $\mathrm{Na}^{+}$ions are excluded from the site due to $\mathrm{Na}^{+} / \mathrm{K}^{+}$exchange since the niobate has the highest selectivity for $\mathrm{K}^{+}$among alkali metal ions at $\mathrm{pH}<3.5$. The presence of $\mathrm{Na}^{+} / \mathrm{K}^{+}$exchange subsequent to the $\mathrm{H}^{+} / \mathrm{Na}^{+}$ exchange reaction is also supported by analysis of the metal ion distribution of the bed. The upper and lower parts ( $2 \mathrm{~g}$ each) of the bed were sampled after the chromatographic operation and the $\mathrm{Na}^{+}$and $\mathrm{K}^{+}$contents of these samples were determined by AAS after dissolved in a mixed solution of $\mathrm{HF}$ and $\mathrm{HNO}_{3}$ while heating at $90{ }^{\circ} \mathrm{C}$, followed by adding an oxalic solution (Table 2 ). The $\mathrm{K}^{+}$ions are exchanged mainly in the upper part of bed but hardly in the lower part. Conversely, the $\mathrm{Na}^{+}$ions are exchanged rarely in the upper part and mainly on the lower part. These results indicate that the $\mathrm{K}^{+}$ions are exchanged preferably to both the lattice protons and $\mathrm{Na}^{+}$ions, and the exchanged $\mathrm{Na}^{+}$ions are excluded from the site by $\mathrm{Na}^{+} / \mathrm{K}^{+}$ exchange. The excluded $\mathrm{Na}^{+}$ions may be exchangeable to the lattice protons just below the $\mathrm{K}^{+}$adsorption band.

Table $2 \mathrm{Na}^{+}$and $\mathrm{K}^{+}$contents of niobate after the chromatographic operation.

\begin{tabular}{ccc}
\hline & $\begin{array}{c}\mathrm{Na}^{+} \text {content } \\
/ \mathrm{mmol} \mathrm{g}^{-1}\end{array}$ & $\begin{array}{c}\mathrm{K}^{+} \text {content } \\
/ \mathrm{mmol} \mathrm{g}^{-1}\end{array}$ \\
\hline Upper part & 0.392 & 1.52 \\
Lower part & 1.53 & 0.002 \\
\hline
\end{tabular}

\subsection{Fractionation Property for Lithium Isotopes}

Lithium uptakes and isotopic separation factors for the ion exchanger, $\left(\mathrm{H}_{3} \mathrm{O}\right)_{8} \mathrm{Nb}_{22} \mathrm{O}_{59}$, are given in Table 3. The lithium uptake increased with a decrease of the amount of immersed niobate on the batch experiment. The $S$ values are 1.017-1.026, depending on $\mathrm{Li}^{+}$uptake. All of the $S$ values are larger than 1, similar to those of inorganic ion-exchangers so far reported.[7-12] Thus the lighter isotope, ${ }^{6} \mathrm{Li}$, is preferentially taken up on $\left(\mathrm{H}_{3} \mathrm{O}\right)_{8} \mathrm{Nb}_{22} \mathrm{O}_{59}$, and the heavier isotope, ${ }^{7} \mathrm{Li}$, is enriched in solution phase.

Table 3 Lithium isotopic separation factors.

\begin{tabular}{cc}
\hline $\begin{array}{c}\mathrm{Li}^{+} \text {uptake } \\
/ \mathrm{mmol} \mathrm{g}^{-1}\end{array}$ & $S$ \\
\hline 0.69 & 1.026 \\
1.40 & 1.019 \\
2.20 & 1.017 \\
\hline
\end{tabular}

The lithium isotope selectivity of an ion-exchanger has been often explained from a correlation with affinity toward alkali metal ions: an ion-exchanger with high affinity to $\mathrm{Li}^{+}$ and/or $\mathrm{Na}^{+}$tends to have a large $S$ value.[7,9,10] For instance, monoclinic antimonic acid with a large $S$ value of 1.020 has high affinity for $\mathrm{Li}^{+}$.[8] Cubic antimonic acid with a large $S$ value of 1.024 has high affinity for $\mathrm{Na}^{+}$and low for $\mathrm{Li}^{+}$and $\mathrm{K}^{+}$.[9] Zirconium phosphate with a NASICON structure has relatively large $S$ value, with high affinity for $\mathrm{Li}^{+}$and $\mathrm{Na}^{+}$, and low for $\mathrm{K}^{+} \cdot[10,11]$ The present niobate may be the first example that shows relatively large $\mathrm{S}$ value with the highest selectivity for $\mathrm{K}^{+}$ions among alkali metal ions.

The lithium ion concentration profile and lithium isotopic ratio, ${ }^{7} \mathrm{Li} /{ }^{6} \mathrm{Li}, \quad$ in elution chromatography are shown in Figure 2. A good chromatogram with clear boundary is obtained in the front part of the lithium elution band, but a slightly nonideal chromatogram with an unclear boundary is obtained in the rear part. The lithium isotopic ratio in the front part is higher than that (12.4) of the isotopic ratio of feed solution, while it is lower in the rear part. The result that ${ }^{7} \mathrm{Li}$ is enriched in the front part of the adsorption band, ${ }^{6} \mathrm{Li}$

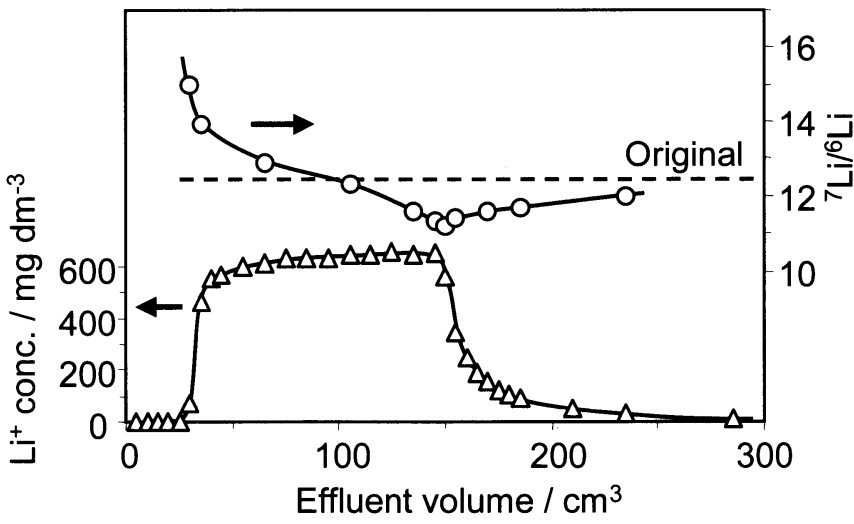

Figure 2 Lithium concentration profile and ${ }^{7} \mathrm{Li} / 6 \mathrm{Li}$ isotopic ratio of chromatography (band operation). Feed solution: $0.05 \mathrm{M} \mathrm{CH} \mathrm{CH}_{3} \mathrm{COOLi}, 240 \mathrm{~cm}^{3}, 12 \mathrm{~cm}^{3} \mathrm{~h}^{-1}$. Eluent: $0.1 M \mathrm{HNO}_{3}, 12 \mathrm{~cm}^{3} \mathrm{~h}^{-1} .{ }^{7} \mathrm{Li} /{ }^{6} \mathrm{Li}$ isotopic ratio of feed solution is 12.4 , and indicated by dashed line. 
in the rear part, correlates well with the result of the batch experiment, where ${ }^{6} \mathrm{Li}$ is preferentially exchanged with the niobate. ${ }^{6} \mathrm{Li}$ may retain in exchanger phase for a longer time than ${ }^{7} \mathrm{Li}$. The maximum and minimum isotopic ratios of the fractions are 15.0 and 11.2, respectively. The lithium isotopic ratio in the rear part increases again after the minimum value. Since the boundary of the band is not so clear as that in the front part, the displacement process may not be ideal due to the slow pore diffusion of $\mathrm{Li}^{+}$ions.

The elementary separation factor, $S$, can be estimated from the lithium concentration profile and isotopic ratios in Figure 2 using the following equation:[13]

$$
S^{\prime}=1+\frac{\sum\left|R_{i}-R_{0}\right| f_{i}}{Q R_{0}\left(1-R_{0}\right)}
$$

where $R_{0}$ and $R_{i}$ are the isotopic mole fractions of ${ }^{6} \mathrm{Li}$ in the inflow and the $i$ th effluent fraction, respectively.; $f_{i}$ the amount of lithium in the $i$ th fraction.; $Q$ the total exchange capacity of the niobate. The summation is taken over all the fractions where ${ }^{6} \mathrm{Li}$ were enriched or depleted. The $Q$ value was evaluated as $59 \mathrm{mmol}$ from the experimental value of ion-exchange capacity, $0.84 \mathrm{mmol} \mathrm{g}^{-1}$, which was determined using a $0.05 \mathrm{M \textrm {CH } _ { 3 } \mathrm { COOLi }}$ solution. The $S^{\prime}$ value was calculated from the front part of the elution curves, assuming that the ${ }^{7} \mathrm{Li} /{ }^{6} \mathrm{Li}$ ratio varies linearly between observed values. The $S^{\prime}$ value was 1.0047 ; this was much smaller than that of batch experiment given in Table 3, as in the case of $\alpha$-titanium phosphate granulated with polyvinyl chloride.[14] The reason may be that the actual $Q$ value during the elution is much smaller than that derived from the ion exchange capacity, because the ion exchange capacity estimated from the $\mathrm{pH}$ titration curve is markedly small in the present elution condition $\left(0.1 \mathrm{MHNO}_{3}\right)$.[6]

\section{Acknowledgement}

A part of this study was financially supported by the Budget for Nuclear Research of the Ministry of Education, Culture, Sports, Science and Technology, based on the screening and counseling by the Atomic Energy Commission.

\section{References}

1) M. Abe and R. Chitrakar, Hydrometallurgy, 19, 117-128 (1987).

2) Y. Miyai, K. Ooi, and S. Katoh, Sep. Sci. Technol., 23, 179-191 (1988).

3) R. Khamizov, D.N. Muraviev, and A. Warshawsky, "Ion Exchange and Solvent Extraction" (Eds. J.A. Marinsky and Y. Marcus), Marcel Dekker Press, New York (1995), 12, 93-148.

4) R. Chitrakar, H. Kanoh, Y. Miyai, K. Ooi, Ind. Eng. Chem. Res., 40, 2054-2058 (2001).

5) N. Kumada, M. Takagi, and N. Kinomura, Chem. Lett., 1996, 989-990.

6) X. Yang, Y. Makita, J. Hosokawa, K. Sakane, and K. Ooi, Chem. Mater., 17, 5420-5427 (2005).

7) Y. Makita, H. Kanoh, T. Hirotsu, and K. Ooi, Chem. Lett., 1998, 77-78.

8) T. Oi, M. Endoh, M. Narimoto, and M. Hosoe, J. Mater. Sci., 35, 509-513 (2000).

9) K. Ooi, Q. Feng, H. Kanoh, T. Hirotsu, and T. Oi, Sep. Sci. Technol, 30, 3761-3770 (1995).

10) T. Oi, Y. Uchiyama, M. Hosoe, and K. Itoh, J. Nucl. Sci. Technol., 36, 1064-1068 (1999).

11) Y. Makita, H. Kanoh, A. Sonoda, T. Hirotsu, and K. Ooi, "Advances in Ion Exchange for Industry and Research" (Eds. P. A. Williams and A. Dyer), RSC press, (1999), 270-275.

12) H. Takahashi, T. Oi, and M. Hosoe, J. Mater. Chem., 12, 2513-2518 (2002).

13) T. Oi, S. Yanase, and H. Kakihana, Sep. Sci. Technol., 22, 2203-2215 (1987).

14) K. Ooi, Y. Miyai, Y. Makita, and H. Kanoh, Sep. Sci. Technol., 34, 1133-1144 (1999). 